\title{
REVIEW OF THE ENVIRONMENTAL EFFECTS ON THE SPACE STATION FREEDOM PHOTOVOLTAIC POWER MODULE
}

\author{
Henry K. Nahra \\ NASA-Lewis Research Center \\ Cleveland, Ohio 44135
}

\begin{abstract}
The purpose of this paper is to provide an overview of the environment in the Low Earth Orbit (LEO), review the interaction of this environment with the Photovoltaic (PV) Power system of the Space Station Freedom, and describe the environmental programs that are designed to investigate the interaction of the LEO environment with the photovoltaic power system. Such programs will support and impact the design of the subsystems of the PV module in order to survive the design lifetime in the LEO natural and induced environment.
\end{abstract}

\section{Introduction}

The Low Earth Orbital environment (LEO) consists the natural neutral and ionized gaseous environment, radiation, orbital debris and micrometeoroid environments. Also included is the induced environment which consists of the contamination, particulate and background illumination environments induced by the presence of the space station in the orbit. The natural and induced LEO environments interact with the space station systems in different ways. The Photovoltaic (PV) Power Module of the Space Station Freedom exhibits interactions with the LEO environment that are electrical, chemical and physical in nature. Electrical interactions are the result of the motion of the PV module through the ionosphere. Chemical interactions are the result of the PV module moving into the natural neutral atomic oxygen (AO) environment. Physical interactions of the PV module systems are the results of the orbital debris and micrometeoroid hypervelocity impacts on the on these systems (Ref. 1).

The purpose of this paper is to furnish a brief description of the PV power module, its interactions with the environment and the in-house programs that are designed to address the interaction issues and provide supporting data to the design of the PV module systems.

\section{Description of the Photovoltaic Power Module}

The PV module of the Space Station Freedom is capable of delivering $18.75 \mathrm{KW}$ to the user. Phase I of the Space Station Program requires $37.5 \mathrm{KW}$ to the user which in turn requires two PV modules for power delivery. The PV module consists of two flexible-deployable lightweight solar arrays for power generation, batteries for energy storage during the sunlight period of the orbit (and for use during the shade period), a thermal control system for the thermal conditioning of the batteries and the frequency conversion units, and two rotational joints for sun vector tracking of the solar arrays during the seasonal variation. Figure 1 illustrates the PV module and its subassemblies (Ref. 2).

\section{Description of the LEO Environment and Its Interaction with the PV Module Natural Environment}

Atomic Oxygen

The neutral environment of the low earth orbit consists of residual gases with concentration that depend on the altitude, and the solar activity. As shown in Figure 2, atomic oxygen has the highest concentration compared to the other neutral constituents of the residual atmosphere. Atomic oxygen is understood to be created by photodissociation of molecular oxygen by the vacuum Ultraviolet Radiation (UV) of wavelength shorter than $200 \mathrm{~nm}$.

Atomic oxygen is highly reactive with polymeric materials. From the early missions of the space shuttle, 
degradation of polymeric films such as Kapton ${ }^{\circledR}$ used extensively in the cargo bay was attributed to atomic oxygen interaction. Materials exhibit different behaviors when exposed to the $\mathrm{AO}$ environment. Polymers with carbon backbone structure exhibit loss of mass and thickness whereas metals develop an oxide layer which either protects the surface or develops microcracks and buckles under its internal stresses. Polymers with silicon backbone structure show more stability in the $\mathrm{AO}$ environment because of the formation of silicon oxide thin films that protect further the surface of the polymer (Ref. 4). Moreover, Fluoropolymers demonstrated on board the space shuttle flight experiments significant stability under exposure to the LEO atomic oxygen. Fluoropolymers such as Polytetrafluoroethylene (PTFE-Teflon $\otimes$ ) and Fluorinated Ethylene-propylene copolymer (FEP) showed more stability than Kapton ${ }^{\circledR}$ because the fluorine-carbon bond energy is higher than hydrogen-carbon bond encountered in Kapton ${ }^{\circledR}$ (Ref. 4). Table 1 reports the reactivities of the different materials exposed to $\mathrm{AO}$ in the space environment. Knowing the total fluence of $\mathrm{AO}$ expected during the mission, these reactivities could be used to predict the total thickness loss of the material (Ref. 5).

The Photovoltaic power module surfaces experience different levels of $\mathrm{AO}$ flux due to their orientations with respect to the velocity vector of the space station. Five orientations of surfaces on the PV module can be identified. The solar surface whose normal is always pointing at the sun receives less $\mathrm{AO}$ flux than the antisolar surface whose normal is 180 degrees from the sun because the latter rams into a slight bulge in the number density which is caused by the solar heating and is located approximately 40 degrees east of the solar noon. The ram surface receives the highest $\mathrm{AO}$ flux in contrast to the wake surface which experiences thermal $\mathrm{AO}$ impingements. The edge-to-sun surface experiences different flux of atomic oxygen on its sides for the same reason mentioned above (Ref. 5). The solar array surfaces are identified with the solar and antisolar surfaces shown in figure 3 . The truss members surface is identified with the ram and wake surfaces. The radiator surfaces are identified with the edgeto-sun surfaces. Figure 3 further illustrates the ori- entation of the aforementioned surfaces relative to each other.

The PV module arrays solar and antisolar surfaces, radiator edge-to-sun and truss ram surfaces are vulnerable to atomic oxygen degradation. The arrays antisolar surface is made of Kapton ${ }^{\circledR}$ which is the material baselined for the solar array substrate. Un less protected from atomic oxygen interaction, it will undergo surface recession and degradation in mechanical properties which could endanger the integrity of the solar arrays. Atomic oxygen degradation of the mast material (S-glass epoxy) is another concern that could be resolved by protection of the mast components. Exposed lubricants also degrade under atomic oxygen. Molybdenum disulfide $\left(\mathrm{MoS}_{2}\right)$ which is a solid lubricant is known to transform into molybdenum oxide giving sulfur oxide gases products. Protection of the lubricated surfaces must be considered in the design of the rotational joints (Ref. 6).

\section{Atomic Oxygen Supporting Programs}

Several programs have been initiated to address some of the atomic oxygen concerns relative to the solar array hardware of the PV module. The Photovoltaic Array Environmental Protection (PAEP) program was initiated under a contract with Lockheed Missiles and Space Corporation to investigate the implementation of different protection schemes into the manufacturing of large panels. By screening protected Kapton ${ }^{\circledR}$ from different manufacturers, Silicon Dioxide $\left(\mathrm{SiO}_{2}\right)$ coated Kapton ${ }^{\circledR}$ that had undergone the array manufacturing processes was found the most stable coating for protection of the solar array substrate when compared to other protected Kapton ${ }^{\circledR}$ options. Due to concerns regarding the defects and pinholes in the $\mathrm{SiO}_{2}$ coating that results from the coating process, the PAEP program is currently investigating alternate materials for use as the blanket substrate. Several commercially available and developmental materials are in the the process of being screened or tested in an atomic oxygen environment to determine what material could be used for the blanket should the coating process of $\mathrm{SiO}_{2}$ on Kapton $\otimes$ not produce coatings that are pinholes and defects free. Results of the alternate blanket study will be completed in time to 
support the panel preliminary design review (Ref. 7).

The Mast Material Test Program (MAMATEP) investigated the effects of atomic oxygen on the mast material (S-glass epoxy). Also investigated were the different protection schemes of this material against atomic oxygen given the longeron shape and bending strain requirements that a mast longeron experiences in the stowed and deployed configurations. The testing included exposure to atomic oxygen, thermal cycling and flexing of protected and unprotected longeron samples. The results indicated that protected samples showed higher resistance to atomic oxygen degradation. Coatings/protective schemes that were tested in this effort were aluminum braid (provided by AEC-Able Engineering Co.), CV-1144 silicone coating (from McGHAN NuSIL), and $\mathrm{Ni} / \mathrm{Au} / \mathrm{InSn}$ eutectic coating (from Composite Optics Inc.). The Atomic oxygen environment used for screening was furnished by an asher in which air is ionized by an RF field to produce a plasma that contained ionized nitrogen and oxygen as well as atomic oxygen in neutral and excited states (Ref. 8).

\section{Charged Particles and Plasma}

Ions and electrons constitute the LEO plasma environment. Electron and ion density and concentration depend on the solar activity, orbital inclination and altitude and time. Near equatorial orbits exhibit higher plasma densities whereas polar orbits are associated with energetic electron fluxes that cause charging of surfaces. The auroral fluxes are attributed to the concentrated magnetic field lines at the earth magnetic poles. Possible interaction of the equatorial plasma environment with the PV module is described by both the parasitic current collection on the blanket which reduces the overall power output and arcing which could cause potential damage to the solar cells on the arrays. The first effect is known to take place in the positive potential region on the solar array relative to the plasma potential whereas the second takes place at the most negative potential end of the array (Ref. 9). High energy penetrating charged particles which originate in the magnetosphere and from cosmic rays are known to penetrate the solar cells on the solar array and induce damage in the lattice structure. This effect is taken into account in the design by oversizing the solar array such that the power delivered at the design lifetime is equal or higher than the required power.

\section{Plasma Interaction Supporting Program}

The PV plasma interaction test objective is to evaluate the effect of the plasma on the solar array operating voltage. Two active panels delivered from the aforementioned PAEP program will be tested in simulated plasma and electron flux environments that simulate the equatorial and polar plasma environments. Plasma is generated by argon plasma generators whereas electron flux is generated by electron guns. In this test, parasitic current collection, arcing threshold, and effect of energetic electron charging will be measured for plasma density levels ranging from 102 to $106 \mathrm{H} / \mathrm{cm}^{3}$. Before and after each run, the current-voltage $(\mathrm{I}-\mathrm{V})$ characteristic curve of the two panels will be measured to monitor any degradation in performance due to plasma interaction. Fig. ure 4 illustrates the test set up of the plasma interaction test. The design and technical support for this test is provided by the Operation and Special Project Division of the Space Station Freedom Directorate and by the Spacecraft Environment office of the Aerospace Technology Directorate.

\section{Micrometeoroid and Debris}

The micrometeoroid and debris environment consists of particles of different density, mass and diameter moving at hypervelocities in the LEO environment. Micrometeoroids are of natural origin, possessing an average velocity of $20 \mathrm{~km} / \mathrm{sec}$ and an average density of $0.5 \mathrm{~g} / \mathrm{cm}^{3}$, whereas orbital space debris are man made, possessing an average relative velocity of 9 to $10 \mathrm{Km} / \mathrm{sec}$ and an average density of $2.8 \mathrm{~g} / \mathrm{cm}^{3}$. The orbital debris and micrometeoroid flux models are described in the Space Station Freedom Natural Environment Definition for Design Document (Ref. 10). As described in this document, space debris flux is dependent on the altitude, orbit inclination, solar activity, particle diameter and future space and launch activities. The micrometeoroid flux model is mainly a function of particle diameter.

Hypervelocity impacts on the solar array, radiator and orbital replacement units (ORU), if not provided for in the design, can cause damage to the surfaces 
and the component functions as well. Impacts on the solar surface of the array can induce damaged/inactive areas on the solar cells which result in degradation of the current output from the solar cell which thereby reduces the power delivery. In the solar array design, this effect is considered, as it is for energetic charged particles, by oversizing the array. Impacts on the radiator surface could result in damaged panels which degrade the performance of the radiator. In the radiator design, this effect is accounted for by either shielding the fluid pipes in the radiator panels if the flow is direct, or by increasing the number of radiator panels if the flow is indirect (i.e. heat pipe radiator). The ORU boxes are shielded in order to withstand impacts by hypervelocity particles. Shielding of the ORU boxes is accomplished using the current technology of bumper shielding.

\section{Micrometeoroid and Debris Supporting Program}

The Mast Impact Damage Assessment Program (MIDAS) objective is to evaluate the damage induced by hypervelocity impacts on the solar array mast longerons. The test consists of impact on S-glass epoxy longerons of different length by a range of projectile diameters in order to deduce the particle diameter that causes a failure of the longerons or significant changes in their mechanical properties. Non destructive evaluation will be performed on the longeron samples before and after impacts using acousto-ultrasonic techniques (Ref. 11). The longeron samples are being prepared for impact at the Hypervelocity Impact Research Laboratory (HIRL) at the NASA Johnson Space Center. In the same facility, two space station array solar cells will be impacted by projectiles of $-400 \mu \mathrm{m}$ in diameter in order to assess the damage induced by this impact on the cover slide, the silicon layers of the cells, and the Kapton ${ }^{\circledR}$ substrate.

\section{Induced Environment}

\section{Induced Contamination}

Contamination environment is induced by the presence of the spacecraft in orbit. It is defined as the molecular and particulate environment that is produced from sources on the spacecraft. Typical contamination sources on the Space Station Freedom are outgassing, thrusters, leaks, and venting. Such sources affect the performance of the astronomical observation payloads performance by increasing the molecular column densities for species that are infrared (IR) active such as $\mathrm{H}_{2} \mathrm{O}$ and $\mathrm{CO}_{2}$ and thereby hinders the infrared observation. Other effects are the particulate release that could have further impact on observation, and deposition on optical/sensitive surfaces (such as solar cells) that degrades the optical properties of the surface (transmission and reflection coefficients) and thereby its performance.

\section{Contamination Supporting Program}

Contamination analysis was initiated at LeRC in order to evaluate the effect of the contamination environment on the first and second flight assemblies. MOLFLUX contamination code, received from Johnson Space Center, was modified and operated by the Engineering Directorate at LeRC in order to geometrically model the first and second flight assemblies and calculate the contamination results such as deposition, and column densities of different species (Ref. 12). This effort was initiated by the PV Module division and continued by the System Engineering and Integration division.

\section{Concluding Remarks}

This paper presented a brief description of the Photovoltaic Power Module, the low earth orbital environment, and the interactions of this environment with the PV power module. This paper presented further the status of the different environmental programs that support the design of the PV module hardware that survives the natural and induced environments and meets the power, lifetime and performance requirements.

The aforementioned natural and induced environments are not the only environmental concerns to the designers of the PV power module. Environmental effects induced by vibration, electromagnetic interference, and induced illumination background, are of concern because of the effects on the payloads and system performance. With the guidance of the environmental requirements and those environmental considerations, it is expected that the space station design, assembly, and utilization can be achieved and maximized at an optimum cost. 


\section{References}

1. Nahra H. K., "Low Earth Orbit Environmental Effects on the Space Station Photovoltaic Power Generation Systems", NASA Technical Memorandum 100230, Prepared for the 1988 ASME Solar Energy Conference, Golden, Colorado, April 10-14, 1988

2. "Power System Description Document," Space Station Freedom Electric Power System, Work Package 04, Contract NAS3-25082, October, 1988

3. Sjolander, G. W., and Bareiss, L. E., "Martin Marietta Atomic Oxygen Beam Facility," 18th International SAMPE Technical Conference, J. T. Hoggatt, S.G. Hill, J.C. Johnson, eds., SAMPE, Azusa, CA, 1986, pp. $722-731$

4. McCargo, M., Dammann, R.A., Cummings, T., and Carpenter, C., "Laboratory Investigation of the Stability of Organic Coatings for Use in a LEO Environment," 3rd European Symposium on Spacecraft Materials in Space Environment, T.D. Guyenne and J.J. Hunt, eds., ESA-SP-232, European Space Agency, Paris, France, 1985, pp. 91-97.

5. Leger, L.J., Visentine J.T., Shliesing, J.A., "A Consideration of Atomic Oxygen Interactions with Space Station," AIAA 85-0476, 1985.

6. Leger, L.J., and Dufrane, K., "Space Station Lubricant Considerations," 21st Aerospace Mechanisms Symposium, Houston, Texas, April 1987.

7. "Photovoltaic Array Environmental Protection," Monthly Progress Report, Contract \# NAS-25079 Prepared for NASA-LeRC, Lockheed Missiles \& Space Company, Sunnyvale, CA, Dec. 1988.

8. Ciancone, M.L., and Rutledge, S.K., "Mast Material Test Program (MAMATEP)," NASA Technical Memorandum 100821, Prepared for Issues of the International Space Station, Sponsored by the American Institute for Aeronautics and Astronautics, Williamsburg, VA, April 1988.

9. Purvis C.K., Ferguson D.C., Snyder, D.B., Grier, N.T., Staskus J.V., and Roche, J.C., "Environmental
Interactions Considerations for the Space Station Solar Array Design," Spacecraft Environment Office, NASA-LeRC, Cleveland, Ohio, 1987.

10. "Space Station Program Natural Environment Definition for Design," Space Station Freedom Program Office, SSP 30425

11. Tatro, C., Private Communication, NASA Kennedy Space Center, Florida, February 1989.

12. Withrow, C., "Electrical Power Systems Contamination Analysis," Preliminary Information Report Prepared for the System Engineering and lntegration and Photovoltaic Power Module Divisions, NASA-LeRC, February, 1989.

\begin{tabular}{|c|c|}
\hline \multicolumn{2}{|c|}{ Table 1} \\
\hline Material & $\begin{array}{c}\text { Reaction Efficiency } \\
(\mathrm{cm} 3 / \text { atom })\end{array}$ \\
\hline Kapton & $3.0 \times 10-24$ \\
\hline Mylar & 3.4 \\
\hline Tedlar & 3.2 \\
\hline Polyethylene & 3.7 \\
\hline PMMA & 3.1 \\
\hline Polyimide & 3.3 \\
\hline Polysulfone & 2.4 \\
\hline 1034C Epoxy & 2.1 \\
\hline 5208/Т300 Ероху & 2.6 \\
\hline Teflon TFE & $<.05$ \\
\hline Teflon FEP & $<.05$ \\
\hline
\end{tabular}




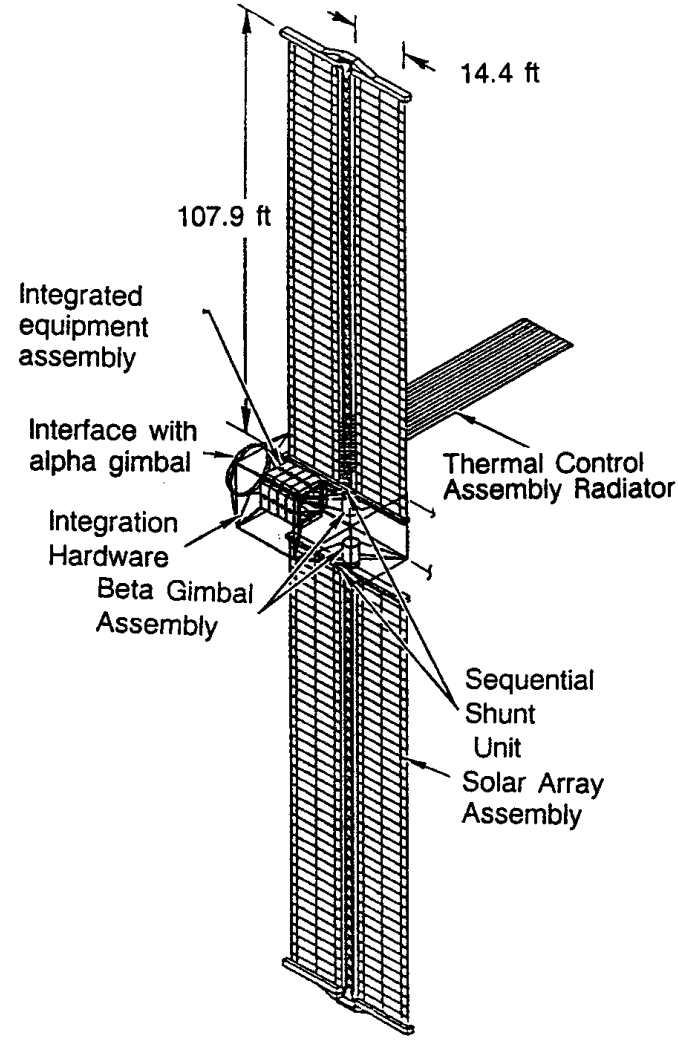

Figure 1. lllustration of the Photovoltaic Power Module and Its subassemblies

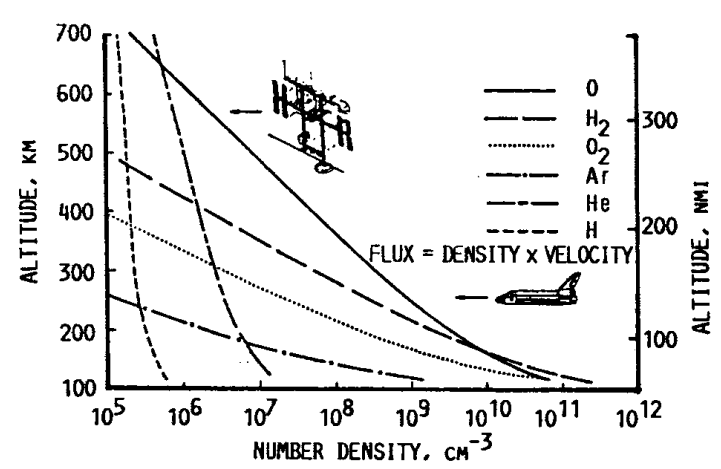

Figure 2. LEO Environment Natural Constituents as Function of Altitude

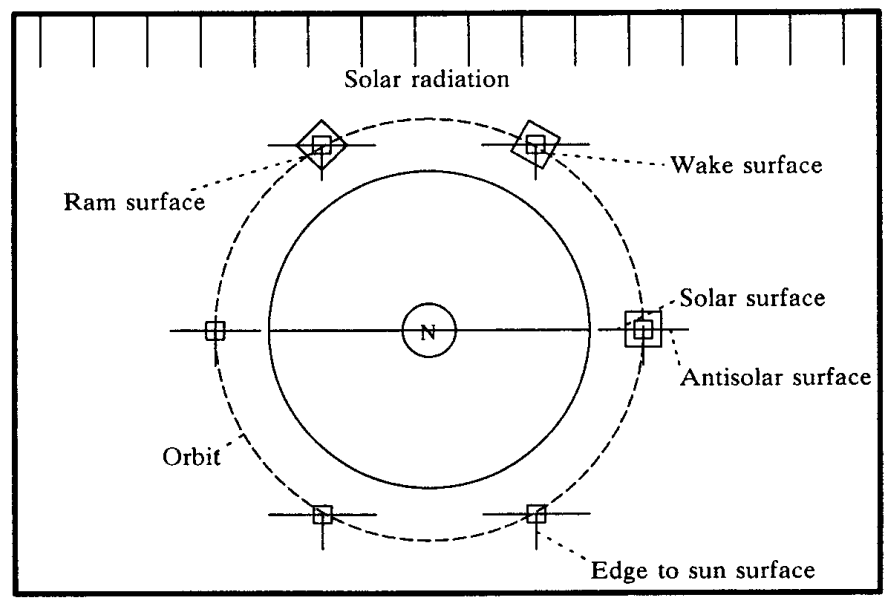

Figure 3. Relative Orientation of the PV module Surfaces in Orbit

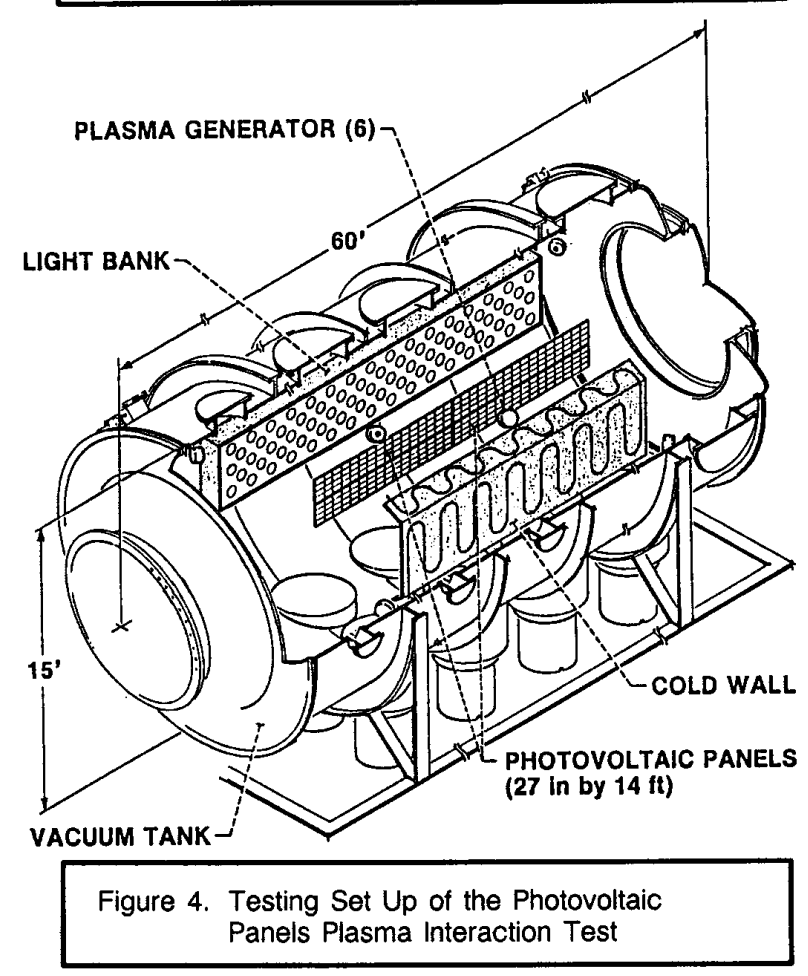

Figure 4. Testing Set Up of the Photovoltaic Panels Plasma Interaction Test 